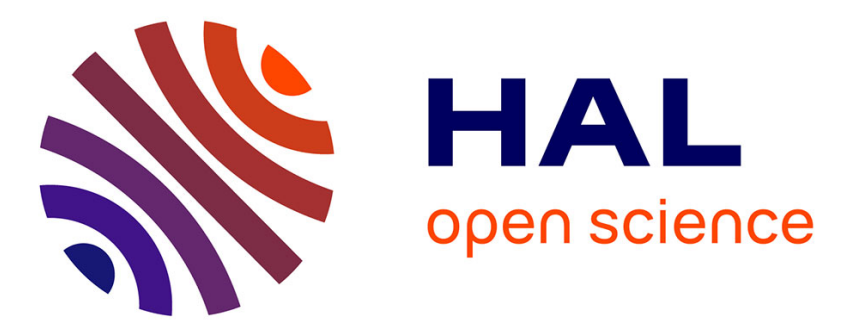

\title{
Bi-exponential decay of Eu(III) complexed by Suwannee River humic substances: Spectroscopic evidence of two different excited species
}

Pascal E. Reiller, Julien Brevet

\section{- To cite this version:}

Pascal E. Reiller, Julien Brevet. Bi-exponential decay of $\mathrm{Eu}(\mathrm{III})$ complexed by Suwannee River humic substances: Spectroscopic evidence of two different excited species. Spectrochimica Acta Part A: Molecular and Biomolecular Spectroscopy [1994-..], 2010, 75 (2), pp.629-636. 10.1016/j.saa.2009.11.029 . cea-00449251

HAL Id: cea-00449251

https://hal-cea.archives-ouvertes.fr/cea-00449251

Submitted on 13 Sep 2019

HAL is a multi-disciplinary open access archive for the deposit and dissemination of scientific research documents, whether they are published or not. The documents may come from teaching and research institutions in France or abroad, or from public or private research centers.
L'archive ouverte pluridisciplinaire HAL, est destinée au dépôt et à la diffusion de documents scientifiques de niveau recherche, publiés ou non, émanant des établissements d'enseignement et de recherche français ou étrangers, des laboratoires publics ou privés.

\section{(1)(1) $\$(0)$}

Distributed under a Creative Commons Attribution - NonCommercial - ShareAlikel 4.0 


\title{
Bi-exponential decay of Eu(III) complexed by Suwannee River humic substances: Spectroscopic evidence of two different excited species.
}

\author{
PASCAL E. REILLER* AND JULIEN BREVET
}

CE Saclay, CEA/DEN/DANS/DPC/SECR, Laboratoire de Spéciation des Radionucléides et des

Molécules, Bâtiment 391-p.c. 33, F-91191 Gif-sur-Yvette CEDEX, France, Université d’Evry Val

d'Essonne, Laboratoire Analyse et Environnement pour la Biologie et l'Environnement, CNRS

UMR 8587, Bâtiment Maupertuis, Boulevard François Mitterrand, F-91025 Evry CEDEX, France.

* Corresponding author e-mail pascal.reiller@,cea.fr

Spectrochimica Acta Part A: Molecular and Biomolecular Spectroscopy 75 (2), 629-636

http://doi.org/10.1016/j.saa.2009.11.029

\begin{abstract}
The bi-exponential luminescence decay of europium (III) complexed by Suwannee River fulvic acid (SRFA) and humic acid (SRHA), is studied in time-resolved luminescence spectroscopy using two different gratings at varying delay after the laser pulse, increasing accumulation time in order to obtain comparable signals. The two hypotheses found in the literature to interpret this bi-exponential decay are (i) a back transfer from the metal to the triplet state of the organic ligand, and (ii) the radiative decay of two different excited species. It is shown that evolutions of the ${ }^{5} \mathrm{D}_{0} \rightarrow{ }^{7} \mathrm{~F}_{0}$ and ${ }^{5} \mathrm{D}_{0} \rightarrow{ }^{7} \mathrm{~F}_{2}$ luminescent transitions are occurring between 10 and $300 \mu$ s delay. First, the ${ }^{5} \mathrm{D}_{0} \rightarrow{ }^{7} \mathrm{~F}_{0}$ transition is decreasing relative to the ${ }^{5} \mathrm{D}_{0} \rightarrow{ }^{7} \mathrm{~F}_{1}$ showing a slightly greater symmetry of the 'slow' component, and is also slightly red-shifted. Second, a slight modification of the ${ }^{5} \mathrm{D}_{0} \rightarrow{ }^{7} \mathrm{~F}_{2}$ transition is also evidencing a slightly different ligand field splitting. No significant modification of the ${ }^{5} \mathrm{D}_{0} \rightarrow{ }^{7} \mathrm{~F}_{1}$ magnetic dipole, which is less susceptible to symmetry changes, is noted in line with expectations from symmetry changes. The ${ }^{5} \mathrm{D}_{0} \rightarrow{ }^{7} \mathrm{~F}_{0}$ transitions are adjusted with either one or two components. The use of a simple component fit seems to be well adapted for representing an average comportment of these heterogeneous compounds, and a two-component fit constrained by the bi-exponential decay parameters and accumulation times yield in the proposition of the spectra for the fast and slow components.
\end{abstract}

\section{Introduction}

Humic substances (HS), mainly humic acids (HA) and fulvic acids (FA), are the main surrogate of natural organic matter (NOM) for the study of its metal complexation strength. Defined from their 
alkaline extraction procedure, HS contain an important functionality inducing an important reactivity. Even if the intimate structure of HS, and thus the structure of formed complexes with metals, is still a matter of debate, a large number of complexation studies have been performed and a wide span of modelling strategies have been used. From the more "mechanistic models" it comes that different populations of sites, or different binding modes, must be accounted to monitor both the acid-base properties of NOM and the complexation isotherms [1-8]. Particularly, in the framework of lanthanides ( $\mathrm{Ln}$ ) and actinides (An) environmental chemistry, Eu(III)-HS complexes have been shown to be multidentate $[6,9-11]$ and involved more than one species [12-14].

The luminescence of lanthanides has been used either to study the complexation strength of HS [6, 9-12, 14-26] and to probe their chemical environment within complexes [12-14, 25-29]. In this field, a large body of work has been done in order to characterize the structure of $\mathrm{Ln} / \mathrm{An}$ (III)-HS complexes including time-resolved luminescence spectroscopy (TRLS) [9-11, 13, 14, 20, 25, 26, 30], and to propose complexation 'stability parameters' [10, 15-19, 21-24]. Throughout these studies, a biexponential decay was noted for $\mathrm{Ln} / \mathrm{Cm}$ (III), which was attributed either to the presence of two radiative decay processes linked to two excited species [9, 26, 30-33], probably in fast exchange, or to an energy back transfer from the excited level of the metal to the ${ }^{3} \pi \pi^{*}$ states of isolated organics around 19,000-25,000 $\mathrm{cm}^{-1}$ [25]. In the case of lanthanides, for thermal reasons this energy back transfer is probable for $\mathrm{Tb}^{3+}, v\left({ }^{5} \mathrm{D}_{4}\right)=20,400 \mathrm{~cm}^{-1}$, but do not seem to be possible for $\mathrm{Eu}^{3+}, v\left({ }^{5} \mathrm{D}_{0}\right)=$ $17,257 \mathrm{~cm}^{-1}$ [34]. Nevertheless, given the available values for the average triplet state of NOM, i.e., from $14,000-15,500$ to $20,500 \mathrm{~cm}^{-1}[35,36]$, it seems that the probability for a back-transfer process, or ligand-to-metal charge transfer [37], to or through humic triplet state from ${ }^{5} \mathrm{D}_{0}$ level of Eu(III) could be favourable. It was anticipated that the apparent bi-exponential decay of $\mathrm{Tb}(\mathrm{III})-\mathrm{HS}$ complexes was related (i) to the 'intrisinc' luminescence decay of the $\mathrm{Ln}(\mathrm{III})-\mathrm{HS}$ complex and (ii) to a back-transfer from the $\mathrm{Ln}(\mathrm{III})$ to the humic chromophore introducing a diffusion parameter in the matrix of the humic aggregate [25]. Otherwise, authors proposed that two, or more, species should be taken into account [12-14, 22, 26]. Yoon et al. [12], Morgenstern et al. [22], and Rabung and Geckeis [26] proposed that the evolution of the double exponential decay vs. $\mathrm{pH}$ was linked to the evolution of the speciation of $\mathrm{Eu}(\mathrm{III})-\mathrm{HS}$ and $\mathrm{Cm}$ (III)-HS complexes, respectively, proposing two [12], three according to $\mathrm{Cm}$ hydrolysis [22], and a heterogeneous distribution [26] of different species with different spectra out of a mostly continuous evolution between $\mathrm{pH}$ 2.8-9.6. After separation of fast dissociating complexes of $\mathrm{Cm}$ (III)-HA by Chelex resin, Monsallier et al. [30] did not evidence a biexponential decay nor a modification of the spectrum of slow dissociating $\mathrm{Cm}$ (III)-HA complex with delay. Rabung and Geckeis also did not note a modification of the spectra at different delay for an 'intact' Cm(III)-HA complex [26]. But these two latter comparisons were done after normalization with the same accumulation time and the obtained spectra at higher delay were inevitably rather noisy. More recently, Freyer et al. proposed evolutions of emission spectra of a Cm(III)-HA complex with delay in $\mathrm{D}_{2} \mathrm{O}$ (fig. 7 in [38]) and in $\mathrm{H}_{2} \mathrm{O}$ (not shown in [38]). Hence, whilst the large body of work available, the structure and photophysics of Ln/An(III)-HS complexes are still a matter of debate.

Two situations are thus possible that are not easily settled: (i) a back-transfer energy is occurring and no modification of the luminescence spectrum of $\mathrm{Ln}^{3+}$ can occur because there should be no perturbation of the ligand field; (ii) two processes from two excited species are contributing to the radiative decay and modifications of the $\mathrm{Ln}(\mathrm{III})-\mathrm{HS}$ complexes should be observed if the ligand fields are sufficiently different; (iii) a combination of the two preceding propositions. In the latter case, modifications of the ${ }^{5} \mathrm{D}_{0} \rightarrow{ }^{7} \mathrm{~F}_{0}$ transition, forbidden for magnetic and electric reasons [39, 40], and also of the ${ }^{5} \mathrm{D}_{0} \rightarrow{ }^{7} \mathrm{~F}_{2}$ 'hypersensitive' electric dipole should be observed, if the ligand field is sufficiently different and the resolution of the observation is adequate. 
Two possibilities are offered to enhance the resolution of a luminescence spectrum in aqueous solution: first, decreasing the temperature to eliminate the non-radiative temperature dependant decay processes [29], and second, increasing the resolution of the spectrometer for the studies in solution at ambient temperature [41]. The aim of this work is to take advantage of a more resolutive grating (1800 lines $\mathrm{mm}^{-1}$ ) to obtain information on the possible modification(s) of Eu(III)-HS complexes luminescence spectra of Suwannee River fulvic acid (SRFA) and humic acid (SRHA) during the luminescence decay.

\section{Material and Methods}

SRFA and SRHA were used as received from the International Humic Substances Society. Europium (III) stock solution was obtained from the dissolution of $\mathrm{Eu}_{2} \mathrm{O}_{3}$ (Johnson Matthey, 99.99\%) in $\mathrm{HClO}_{4}$. The $\mathrm{Eu}(\mathrm{III})-\mathrm{HS}$ complexes were formed in $\mathrm{HS}$ solutions as in ref. [10, 11], with $10^{-5}$ moleu $\mathrm{L}^{-1}$ and $200 \mathrm{mg}_{\mathrm{HS} \mathrm{L}} \mathrm{L}^{-1}$; all of $\mathrm{Eu}(\mathrm{III})$ is then considered to be complexed by HS [10] even if the ratios between $\mathrm{Eu}$ and the number of available sites are slightly different [42, 43]. The ionic strength was fixed with $\mathrm{NaClO}_{4}$ to 0.1 mol L${ }^{-1}$ and $\mathrm{pH}$ was adjusted using freshly prepared $\mathrm{NaOH}$ and $\mathrm{HClO}_{4}$. The $\mathrm{pH}$ measurements were done using a combined-glass electrode (Radiometer Analytical XC111) calibrated for its linear response with a $0.01 \mathrm{~mol} \mathrm{~L}^{-1} \mathrm{HClO}_{4}$ solution, an equimolar $0.02 \mathrm{~mol} \mathrm{~L}^{-1}$ $\mathrm{NaH}_{2} \mathrm{PO}_{4} / \mathrm{Na}_{2} \mathrm{HPO}_{4}$ solution and an equimolar $0.02 \mathrm{~mol} \mathrm{~L}^{-1} \mathrm{Na}_{2} \mathrm{CO}_{3} / \mathrm{NaHCO}_{3}$ solution, all containing $\mathrm{NaClO}_{4}$ to keep $\left[\mathrm{Na}^{+}\right]$constant at $0.1 \mathrm{~mol} \mathrm{~L}^{-1}(\mathrm{pH}=2.0,6.8$, and 9.9 respectively). The electrode filling solution was modified with $\mathrm{NaClO}_{4} 0.1 \mathrm{~mol} \mathrm{~L}^{-1}, \mathrm{NaCl} 10^{-2}$ mol L $\mathrm{L}^{-1}$ to prevent $\mathrm{KClO}_{4}$ precipitation in the frit of the electrode.

Before measurement the $\mathrm{pH}$ was adjusted to 5 to minimize hydrolysis and carbonate species of $\mathrm{Eu}(\mathrm{III})$ and maximize the $\mathrm{Eu}(\mathrm{III})-\mathrm{HS}$ complex formation. Under these conditions, $99 \%$ of $\mathrm{Eu}(\mathrm{III})$ is complexed in humic form $[10,44]$.

$\mathrm{Eu}$ (III) was used to probe its laser induced luminescence properties in contact with humic substances. The observed luminescence corresponds to the ${ }^{5} \mathrm{D}_{0} \rightarrow{ }^{7} \mathrm{~F}_{0}$ (electric and magnetic dipole forbidden, maximum around $580 \mathrm{~nm}$ ), the ${ }^{5} \mathrm{D}_{0} \rightarrow{ }^{7} \mathrm{~F}_{1}$ transition (magnetic dipole, maximum around 593 $\mathrm{nm}$ ), and the ${ }^{5} \mathrm{D}_{0} \rightarrow{ }^{7} \mathrm{~F}_{2}$ 'hypersensitive' transition (electric dipole, maximum around $615 \mathrm{~nm}$ ). These emission lines come from transitions of the ${ }^{5} \mathrm{D}_{0}$ excited state to the ground ${ }^{7} \mathrm{~F}_{\mathrm{j}}$ manifold [45].

The excitation laser beam was generated by a $355 \mathrm{~nm}$ tripled output of a Continuum Nd-YAG laser, coupled to an optical parametric oscillator system (Panther II, Continuum, USA). The wavelength was tuned to $394.6 \mathrm{~nm}$, which corresponds to the ${ }^{7} \mathrm{~F}_{0} \rightarrow{ }^{5} \mathrm{~L}_{6}$ transition of $\mathrm{Eu}(\mathrm{III})$, providing about $1 \mathrm{~mJ}$ of energy in a $5 \mathrm{~ns}$ pulse with a repetition rate of $10 \mathrm{~Hz}$. After inner conversion the ${ }^{5} \mathrm{D}_{1}$ level is transferring energy to the ${ }^{5} \mathrm{D}_{0}$ level and the transitions to the ${ }^{7} \mathrm{~F}_{\mathrm{j}}$ manifold can be observed. Additionally, HS are able to absorb the laser emission at $394.6 \mathrm{~nm}$ and part of the absorbed energy is transferred from the ${ }^{3} \pi \pi^{*}$ triplet level to the central europium ion. The time-resolved luminescence signal is collected at $90^{\circ}$ and focused into a Acton spectrometer (slit $1 \mathrm{~mm}$ ) using either a 600 lines $\mathrm{mm}^{-1}$ or a 1800 lines $\mathrm{mm}^{-1}$ grating. The signal is collected during a gate width $W=300 \mu \mathrm{s}$, after a gate delay $D=10 \mu \mathrm{s}$ after excitation by the laser flash. The accumulation time was adjusted from the intensities obtained at the different delays in agreement with ref. [41]. Emission spectra were recorded using a CCD camera cooled at $-15^{\circ} \mathrm{C}$.

The absorbance values at $394 \mathrm{~nm}$ of SRFA and SRHA are 0.429 and 0.947, respectively; the prefilter effect is reasonable compared to other samples [Table 3 in ref. 41], and the presented spectra did 
not require any smoothing treatment. The absorbance at $591 \mathrm{~nm}$ is 0.017 for SRFA the post filter effect could be neglected.

\section{Results and Discussions}

\subsection{Evolution of the spectra under comparable acquisition conditions at 600 lines $\mathrm{mm}^{-1}$.}

The luminescence decays of the various Eu(III)-HS complexes can be described by a bi-exponential decay function. For our fully integrative system, it comes:

$$
F_{\mathrm{i}}=\sum_{i=1}^{\mathrm{n}} \int_{D}^{D+W} F_{i}^{\mathrm{o}} \exp \left(-\frac{\mathrm{t}}{\tau_{i}}\right) \mathrm{dt}=\sum_{i=1}^{\mathrm{n}} F_{i}^{\mathrm{o}} \tau_{i} \exp \left(-\frac{D}{\tau_{i}}\right)\left(1-\exp \left(-\frac{W}{\tau_{i}}\right)\right)
$$

where $F$ is the luminescence signal, $F^{\circ}{ }_{i}$ and $\tau_{i}$ are the initial luminescence and the decay time of component $i$, respectively, $D$ the delay after the laser excitation and $W$ the gate width.

First, the eventual photochemical reactions [30] of humic substances were tested. The acquisitions of the spectra reported on Figure 1A,B for Eu(III)-SRFA and Eu(III)-SRHA, respectively, were not done in a 'classical' way. In order to obtain spectra that can be compared with almost the same signal, the number of accumulations was corrected at each delay $D$, i.e., 10, 50, 100, 200, and $300 \mu \mathrm{s}$, using the gate width $W=300 \mu \mathrm{s}$, from the evolution of the bi-exponential decay obtained previously [41]. Nevertheless, this induces a decrease in the signal-to-noise ratio. These spectra indicate a strong interaction with the humic medium from the asymmetry ratio ${ }^{5} \mathrm{D}_{0} \rightarrow{ }^{7} \mathrm{~F}_{2} /{ }^{5} \mathrm{D}_{0} \rightarrow{ }^{7} \mathrm{~F}_{1}$, i.e., 3.0 and 3.9, based on peak area, for Eu(III)-SRFA and Eu(III)-SRHA, respectively. Also one can see on Figure 2, that no loss in $\mathrm{Eu}(\mathrm{III})$ fluorescence emission can be evidenced on ${ }^{5} \mathrm{D}_{0} \rightarrow{ }^{7} \mathrm{~F}_{1}$ nor on ${ }^{5} \mathrm{D}_{0} \rightarrow{ }^{7} \mathrm{~F}_{2}$ transitions based on peak area. The accumulation times and induced absorbed energies for the different delays are reported in Table 1: a negligible photo-degradation is then awaited [46]. However, a significant decrease of the ${ }^{5} \mathrm{D}_{0} \rightarrow{ }^{7} \mathrm{~F}_{0}$ transition is evidenced on Figure 2 from the peak areas and from the ${ }^{5} \mathrm{D}_{0} \rightarrow{ }^{7} \mathrm{~F}_{1} /{ }^{5} \mathrm{D}_{0} \rightarrow{ }^{7} \mathrm{~F}_{0}$ ratio when the ${ }^{5} \mathrm{D}_{0} \rightarrow{ }^{7} \mathrm{~F}_{2} /{ }^{5} \mathrm{D}_{0} \rightarrow{ }^{7} \mathrm{~F}_{1}$ ratio is constant. The use of the more resolutive grating will give more information about this decrease of the ${ }^{5} \mathrm{D}_{0} \rightarrow{ }^{7} \mathrm{~F}_{1} /{ }^{5} \mathrm{D}_{0} \rightarrow{ }^{7} \mathrm{~F}_{0}$ ratio. 

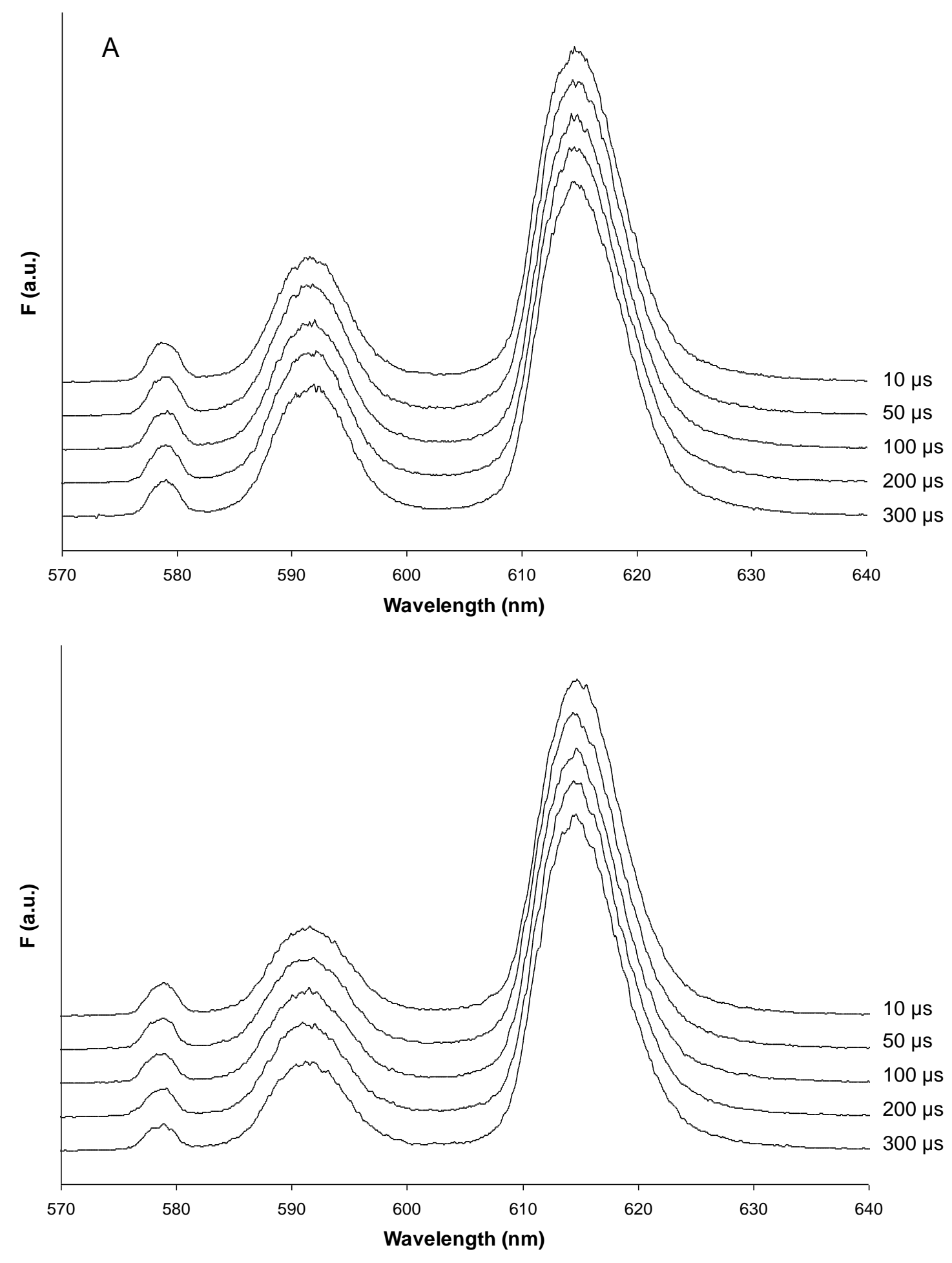

Figure 1. Luminescence spectrum of Eu(III)-SRFA (A) and $\mathrm{Eu}$ (III)-SRHA (B) complexes at $\lambda_{\mathrm{exc}}=$ $394.6 \mathrm{~nm}$ at different delays, $W=300 \mu \mathrm{s}, \mathrm{pH}=5$, and 600 line $\mathrm{mm}^{-1}$, increasing the number of accumulation in order to obtain the same signal on the ${ }^{5} \mathrm{D}_{0} \rightarrow{ }^{7} \mathrm{~F}_{1}$ transitions; the spectra are normalized to counterweight the slight laser energy variations. 
Table 1: Parameters of the spectra acquisition of Figures 1 and 3.

Grating 600 lines $\mathrm{mm}^{-1}$

\begin{tabular}{|c|c|c|c|c|c|c|c|c|c|c|}
\hline Delay $(\mu s)$ & 10 & & 50 & & 100 & & 200 & & 300 & \\
\hline & $\mathrm{Nb}$ Acc & $\mathrm{mJ} / \mathrm{mg}$ & $\mathrm{Nb}$ Acc & $\mathrm{mJ} / \mathrm{mg}$ & $\mathrm{Nb}$ Acc & $\mathrm{mJ} / \mathrm{mg}$ & $\mathrm{Nb}$ Acc & $\mathrm{mJ} / \mathrm{mg}$ & $\mathrm{Nb}$ Acc & $\mathrm{mJ} / \mathrm{mg}$ \\
\hline SRFA & 600 & 1.5 & 925 & 2.3 & 1340 & 3.4 & 2900 & 7.3 & 5000 & 12.5 \\
\hline SRHA & 1000 & 2.5 & 1873 & 4.7 & 2730 & 6.8 & 5154 & 12.9 & 8740 & 21.9 \\
\hline \multicolumn{11}{|c|}{ Grating 1800 lines $\mathrm{mm}^{-1}$} \\
\hline \multirow[t]{2}{*}{ Delay $(\mu s)$} & 10 & & 50 & & 100 & & 200 & & 300 & \\
\hline & $\mathrm{Nb}$ Acc & $\mathrm{mJ} / \mathrm{mg}$ & $\mathrm{Nb}$ Acc & $\mathrm{mJ} / \mathrm{mg}$ & $\mathrm{Nb}$ Acc & $\mathrm{mJ} / \mathrm{mg}$ & $\mathrm{Nb}$ Acc & $\mathrm{mJ} / \mathrm{mg}$ & $\mathrm{Nb}$ Acc & $\mathrm{mJ} / \mathrm{mg}$ \\
\hline SRFA & 1000 & 2.5 & 1440 & 3.6 & 2204 & 5.5 & 4500 & 11.3 & 8400 & 21.0 \\
\hline SRHA & 2000 & 5.0 & 3564 & 8.9 & 5332 & 13.3 & 9980 & 25.0 & 16867 & 42.2 \\
\hline
\end{tabular}

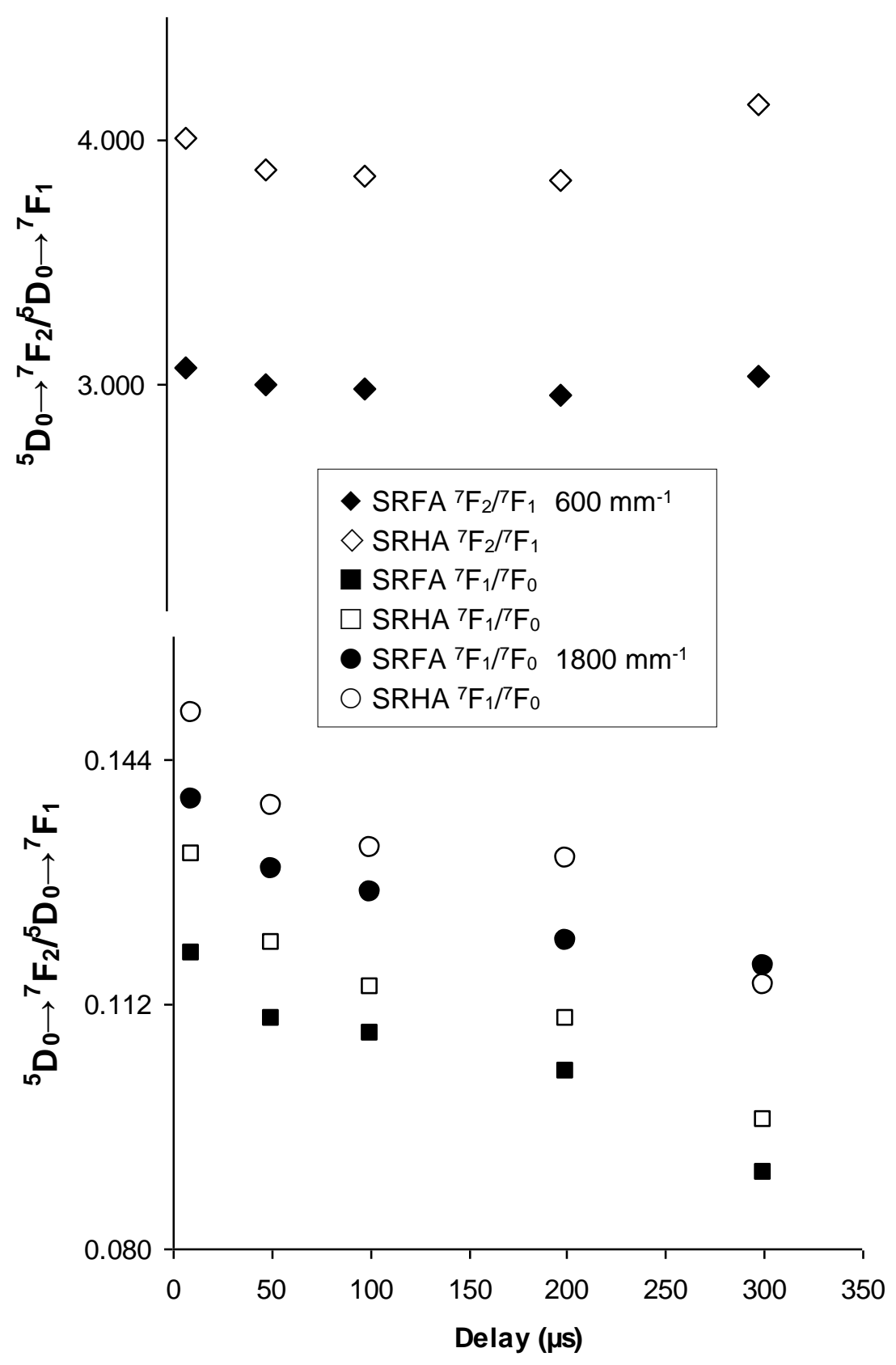

Figure 2: Evolution of the experimental ${ }^{5} \mathrm{D}_{0} \rightarrow{ }^{7} \mathrm{~F}_{2} /{ }^{5} \mathrm{D}_{0} \rightarrow{ }^{7} \mathrm{~F}_{1}$ (diamonds) and ${ }^{5} \mathrm{D}_{0} \rightarrow{ }^{7} \mathrm{~F}_{0} /{ }^{5} \mathrm{D}_{0} \rightarrow{ }^{7} \mathrm{~F}_{1}$ (squares $600 \mathrm{~mm}^{-1}$, circles $1800 \mathrm{~mm}^{-1}$ ) peak area ratios of $\mathrm{Eu}(\mathrm{III})$-HS complexes at $10^{-5} \mathrm{~mol}_{\mathrm{Eu} \mathrm{L}} \mathrm{L}^{-1}$ and $200 \mathrm{mg}_{\mathrm{HS} \mathrm{L}} \mathrm{L}^{-1}$ on Figure 1 and Figure $3 \mathrm{AD}$, for SRFA (full symbols) and SRHA (empty symbols). 


\subsection{Evolution of ${ }^{5} D_{0} \rightarrow{ }^{7} F_{0}$ at 1800 line $\mathrm{mm}^{-1}$ grating.}

Due to the increase in resolution and the lesser convolution with the spectrograph's parameters, the ${ }^{5} \mathrm{D}_{0} \rightarrow{ }^{7} \mathrm{~F}_{0} /{ }^{5} \mathrm{D}_{0} \rightarrow{ }^{7} \mathrm{~F}_{1}$ and ${ }^{5} \mathrm{D}_{0} \rightarrow{ }^{7} \mathrm{~F}_{2} /{ }^{5} \mathrm{D}_{0} \rightarrow{ }^{7} \mathrm{~F}_{1}$ ratios obtained hereafter are inevitably different from what they appeared in the previous section. As for the 600 lines $\mathrm{mm}^{-1}$ grating, the accumulation times and absorbed energies are reported in Table 1; a negligible photo-degradation is awaited. A slight normalization was done in order to get rid of the laser energy variations for these particularly long integration times. The spectra for the two complexes acquired with the 1800 lines $\mathrm{mm}^{-1}$ grating are presented on Figure 3.

First, we will focus on the ${ }^{5} \mathrm{D}_{0} \rightarrow{ }^{7} \mathrm{~F}_{0}$ transition around $579 \mathrm{~nm}$. This transition is much more intense due to the higher resolution, and lower convolution with the spectrometer's parameters. This results in significantly different ${ }^{5} \mathrm{D}_{0} \rightarrow{ }^{7} \mathrm{~F}_{0} /{ }^{5} \mathrm{D}_{0} \rightarrow{ }^{7} \mathrm{~F}_{1}$ area ratios of 0.87 and 0.99 for Eu(III)-SRFA and $\mathrm{Eu}(\mathrm{III})-\mathrm{SRHA}$, respectively. As seen previously, the non-degenerated ${ }^{5} \mathrm{D}_{0} \rightarrow{ }^{7} \mathrm{~F}_{0}$ transition is clearly decreasing and very slightly red shifted (Figure 3C,F). It seems that for Eu(III)-SRFA and $\mathrm{Eu}(\mathrm{III})-\mathrm{SRHA}$ the two components proposed for other HS [12-14] can also be seen by the decrease in the ${ }^{5} \mathrm{D}_{0} \rightarrow{ }^{7} \mathrm{~F}_{0} /{ }^{5} \mathrm{D}_{0} \rightarrow{ }^{7} \mathrm{~F}_{1}$ ratios on Figure 2 . This decrease is linearly correlated with delay for both extracts. There is no apparent reason for this linear correlation with delay apart from a too narrow observation window because both components already contribute more or less equally to the luminescence signal at a $10 \mu$ s delay. Knowing that the luminescence decay is (bi)exponential, one could await an exponentially dependant expression. The evolution of ${ }^{5} \mathrm{D}_{0} \rightarrow{ }^{7} \mathrm{~F}_{0} /{ }^{5} \mathrm{D}_{0} \rightarrow{ }^{7} \mathrm{~F}_{1}$ ratios for $\mathrm{Eu}(\mathrm{III})-\mathrm{SRHA}$ complex is very much alike the Eu(III)-SRFA one. One can note that the ${ }^{5} \mathrm{D}_{0} \rightarrow{ }^{7} \mathrm{~F}_{0} /{ }^{5} \mathrm{D}_{0} \rightarrow{ }^{7} \mathrm{~F}_{1}$ intensity ratio for SRHA is greater than the SRFA one. This reflects the fact that when the delay is increasing, ${ }^{5} \mathrm{D}_{0} \rightarrow{ }^{7} \mathrm{~F}_{0}$ intensities of Eu(III)-SRFA and Eu(III)-SRHA tend to be closer ending in the same value $( \pm 2 \sigma)$ of $0.72 \pm 0.02$ and $0.74 \pm 0.05$ for Eu(III)-SRFA and Eu(III)-SRHA, respectively, at $D=300 \mu \mathrm{s}$.

The use of ${ }^{5} \mathrm{D}_{0} \rightarrow{ }^{7} \mathrm{~F}_{0}$ transition was either dedicated to define the number of species involved due to its non-degenerescence after direct ${ }^{7} \mathrm{~F}_{0} \rightarrow{ }^{5} \mathrm{D}_{0}$ excitation or to the determination of the charge of the complex [47-49]. Its appearance in the spectra is correlated with the lowering of the complex's symmetry $[39,40]$. The decompositions of the non-degenerated ${ }^{5} \mathrm{D}_{0} \rightarrow{ }^{7} \mathrm{~F}_{0}$ transitions were often done using Lorentzian-Gaussian peak [50].

$$
\mathrm{I}_{\mathrm{i}}=\mathrm{I}_{\max , \mathrm{i}} \frac{\exp \left[-0.5\left(\frac{\lambda_{\mathrm{i}}-\lambda_{0, \mathrm{i}}}{\sigma_{\mathrm{LG}, \mathrm{i}}}\right)^{2}\right]}{\left(\frac{\lambda_{\mathrm{i}}-\lambda_{0, \mathrm{i}}}{\sigma_{\mathrm{LG}, \mathrm{i}}}\right)^{2}+1}
$$

Using non-linear regression, the different parameters, i.e., $\mathrm{I}_{\max , \mathrm{i}}$ the maximum intensity of the $\mathrm{i}^{\text {th }}$ peak, $\lambda_{0, \mathrm{i}}$ its position of its maximum $(\mathrm{nm}), \sigma_{\mathrm{LG}, \mathrm{i}}$ its 'standard deviation' linked to its full-width at midheight $w(\mathrm{~nm}), 1.46 \times \sigma_{\mathrm{LG}, \mathrm{i}}=w[50]$, can be obtained. The associated standard deviations of the parameters, covariance and correlation matrices are calculated using the SolverAid macro [51]. 

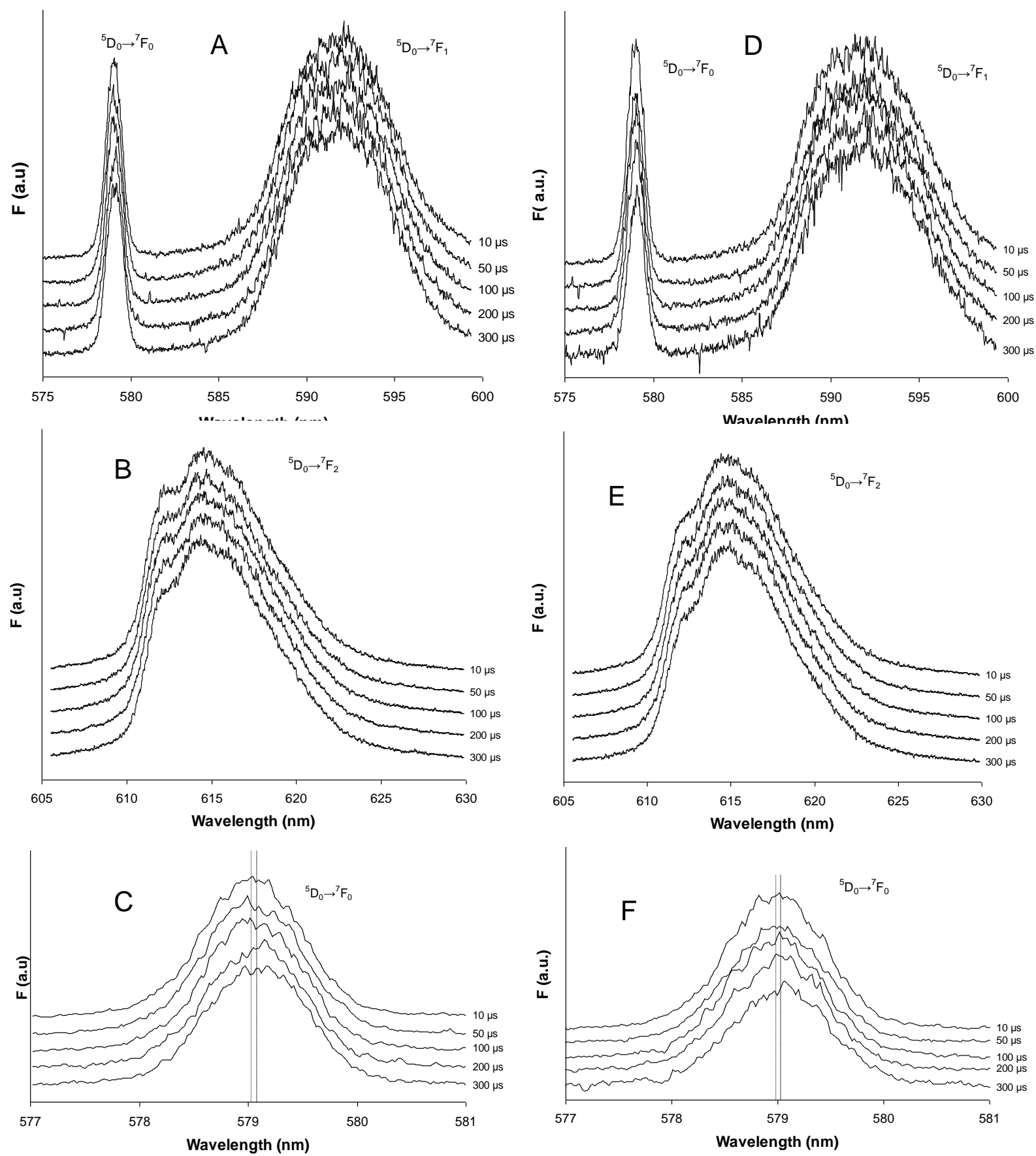

Figure 3: Luminescence spectra of Eu(III)-SRFA (A to C) and Eu(III)-SRHA (D to F) complexes at $\lambda_{\text {exc }}=394.6 \mathrm{~nm}$ at different delays, $W=300 \mu \mathrm{s}, \mathrm{pH}=5$, increasing the number of accumulation in order to obtain the same signal on the ${ }^{5} \mathrm{D}_{0} \rightarrow{ }^{7} \mathrm{~F}_{1}$ transitions, in the wavelength spans $575-600 \mathrm{~nm}$ $(\mathrm{A}, \mathrm{D})$, and $605-630 \mathrm{~nm}(\mathrm{~B}, \mathrm{E})$, and the magnification of the 577-581 nm wavelength span (C, F); the spectra are normalized to counterweight the slight laser energy variations.

Although fits with two components were proposed for HS [12-14], one can think that a fit by a single component would give an averaged value of the Eu(III) comportment in HS (Figure S1 and Table S1 from the Supplementary Material). The values of $\sigma_{L G}$ are more or less constant giving $w \approx 1.05$ that is comparable to former determinations in direct ${ }^{7} \mathrm{~F}_{0} \rightarrow{ }^{5} \mathrm{D}_{0}$ excitation [12-14]. Conversely, the evolutions of $\mathrm{I}_{\text {max,i, }}$, i.e., ${ }^{5} \mathrm{D}_{0} \rightarrow{ }^{7} \mathrm{~F}_{0} /{ }^{5} \mathrm{D}_{0} \rightarrow{ }^{7} \mathrm{~F}_{1}$, and $\lambda_{0, \mathrm{i}}$ are opposed: as the delay is increasing the maximum intensity of the ${ }^{5} \mathrm{D}_{0} \rightarrow{ }^{7} \mathrm{~F}_{0} /{ }^{5} \mathrm{D}_{0} \rightarrow{ }^{7} \mathrm{~F}_{1}$ ratio is decreasing from $0.85 \pm 0.01$ to $0.72 \pm 0.00_{03}$, and $\lambda_{0}$ is slightly redshifted of 0.05 for both SRFA and SRHA. 
Here for the Eu(III)-SRFA and Eu(III)-SRHA complexes the mono component peak fits are in agreement with the maximum emission of either a $\mathrm{EuCl}^{2+}$ complex or $\mathrm{Eu}(\mathrm{III})$ in methanol directly excited in the ${ }^{7} \mathrm{~F}_{0} \rightarrow{ }^{5} \mathrm{D}_{0}$ transition $[48,52]$. This indicates the low average charge of the "complexing unit', i.e., around -0.9 and -1.3 at 10 and $300 \mu$ s delay, respectively [48]. One should note that this is not the charge of a 'humic molecule', which is still up to now not really defined. From the relation between the number of coordinated ligands $\mathrm{CN}$ and $v_{0}\left(\mathrm{~cm}^{-1}\right)$ proposed for the ${ }^{5} \mathrm{D}_{0} \rightarrow{ }^{7} \mathrm{~F}_{0}$ transition [49], i.e., $\mathrm{CN}=0.237 \Delta v+0.638$, values from ${ }^{\mathrm{SRFA}} \mathrm{CN}=2.0$ and ${ }^{\mathrm{SRHA}} \mathrm{CN}=1.6$ at $10 \mu$ s delay, to ${ }^{\mathrm{SRFA}} \mathrm{CN}=$ 2.3 and ${ }^{\mathrm{SRHA}} \mathrm{CN}=1.9$ at $300 \mu$ s delay, are obtained; these values are not significantly different $(\mathrm{CN} \pm$ 0.7 ) and are in line with the complexation of $\mathrm{Eu}(\mathrm{III})$ through a multidentate form [10]. As previously seen, the estimations from $\tau_{2}$ of the number of water molecules remaining in the first hydration sphere, 7 and 5 for Eu(III)-SRFA and Eu(III)-SRHA, respectively, are also indications of multidentate complexation [41]. Rabung and Geckeis proposed about the same number of remaining water molecules for Cm(III) complexed by Gorleben (Germany) HA [26]. Nevertheless, one can question the validity of $\mathrm{CN}$ and number of water molecules expressions for complex mixtures as humic substances. As a matter of fact quenching effect from humic chromophores may have an influence on non-radiative de-excitation pathways of the complexed metal even if not in direct contact within the humic aggregates. Moreover, these expressions have not yet been validated in this case.

The calculation for the fast decay time cannot be done for several reasons. First the proposed empirical expressions are given relative to the aqueous $\mathrm{Eu}^{3+}$, which have a decay time value circa 110 $\mu \mathrm{s}$. Up to now, the values measured for $\tau_{1}$ are ranging from 20 to $60 \mu \mathrm{s}[11,41]$ depending on total $\mathrm{Eu}$ and HA concentrations and origin of humic extracts. This means that (i) part of the luminescence of $\mathrm{Eu}$ is quenched within the humic structure by chromophores that may not be in direct complexation, and/or (ii) a fast exchanging process is occurring within the structure. The energy transfer could be due either to a Förster resonance energy transfer (FRET) or Dexter energy transfer, respectively [53]. FRET can be operative over distances as long as $100 \mathrm{~nm}$ depending on the particular donor-acceptor pair. The energy transfer according to Dexter requires an overlap of the electron orbital of the donor and the acceptor. As the distance between the ligands and Eu(III) is relatively short, the Dexter energy transfer could be favoured. So far, in the case of HA, the link between the binding sites and the chromophores engaged in the energy transfer has not been demonstrated unequivocally. Thus, the resonance phenomenon cannot be ruled out.

The decomposition in two peaks of ${ }^{5} \mathrm{D}_{0} \rightarrow{ }^{7} \mathrm{~F}_{0}$ transitions using Equation (2) was done for the five delays altogether and adjusting only $\mathrm{I}_{\mathrm{max}, \mathrm{i}}, \lambda_{0, \mathrm{I}}$, and $\sigma_{\mathrm{LG}, \mathrm{i}}$ : the different proportions of the two species were fixed by the bi-exponential decays' fits proposed otherwise [41], and the accumulation times. The obtained fits are reported on Figure S2 (A to E) for SRFA and Figure S2 (F to J) for SRHA, from Supplementary Material; the parameters of the fits and the correlation matrices are given in Table S2. The difference between the peak maximum, i.e., $\Delta \lambda_{0}=\lambda_{0,2}-\lambda_{0,1}$, are of $0.10 \pm 0.01$ for SRFA, and $0.07 \pm 0.01 \mathrm{~nm}$ for SRHA, which is lower than previously obtained from soil HS, i.e., $\Delta \lambda_{0}=0.2 \mathrm{~nm}$ $[13,14]$. The $\sigma_{\mathrm{LG}, \mathrm{I}}$ values are not statistically different around $0.7 \mathrm{~nm}\left(w_{\mathrm{i}} 1-1.1 \mathrm{~nm}\right)$, not very different from the single component fits, and both $\mathrm{I}_{\mathrm{max}, 1}$ and $\lambda_{0,1}$ are different from the single component fits situation: both $\mathrm{I}_{\max , 2}$ and $\lambda_{0,2}$ correspond to the mono-exponential fits at $300 \mu \mathrm{s}$. This means that even the two component situation could be the result of two different populations of environments and not two well-defined environments. This can be reconciled to the continuous description of acid-base and complexation properties of humic substances $[1,2,4,7]$.

The $w$ values from the fits can be discussed in the light of the literature data. The full-width at midheight of 'simple' complexes were found to be $w=0.2-0.5 \mathrm{~nm} ; w$ viz. $0.2 \mathrm{~nm}$ for $\mathrm{EuCH}_{3}(\mathrm{COO})_{\mathrm{n}}{ }^{3-\mathrm{n}}$ 
complexes $(1 \leq \mathrm{n} \leq 3)$ [54], $w$ viz. $0.3 \mathrm{~nm}$ in the case of tris(2,2,6,6-tetramethyl-3,5-heptanedionato)$\mathrm{Eu}(\mathrm{III})$ at $298 \mathrm{~K}$ [37], w viz. 0.4-0.5 $\mathrm{nm}$ can be estimated for dipicolinato-Eu(III) [28] and for iminodiaceto-Eu(III) [47], and a $w$ viz. $0.2 \mathrm{~nm}$ can be estimated for Eu(III) complexed to the 5-fold sites of the icosahedral satellite tobacco necrosis virus [55]. For humic substances, Shin et al. [13] proposed two contributions for $\mathrm{Eu}(\mathrm{III})$ soil FA and soil HA complexes: $\Delta \lambda_{0} \approx 0.2 \mathrm{~nm}$, and ${ }^{\mathrm{FA}} w$ viz. 0.6 $\mathrm{nm}$, and ${ }^{\mathrm{HA}}$ w viz. $1.0 \mathrm{~nm}$. Later, Shin and Choppin proposed two component peaks for Aldrich HA with $\sigma_{\mathrm{LG}}=10-19 \mathrm{~cm}^{-1}$ as function of Eu/HA concentration ratio [14], yielding a total ${ }^{\mathrm{HA}} w$ viz. $0.9 \mathrm{~nm}$. There seems to be an agreement between $w$ values for dipicolinato-Eu(III) [28], iminodiaceto- $\mathrm{Eu}$ (III) [47], and Eu(III)-soil FA [13, 14], but not for Eu(III)-soil HA or Eu(III)-PAHA. Here, we obtain $\mathrm{SRFA} \approx 1.05 \pm 0.02 \mathrm{~nm}$ and ${ }^{\mathrm{SRHA}} w \approx 1.06 \pm 0.01 \mathrm{~nm}$ for a single component fit; as said earlier, the $w$ values do not result in 'simple' complexation environments, and should thus be the caused by two (or more) 'populations of environments'. This is not surprising as the HS mixtures are considered as continuum of chromophores [56] or of functional groups $[2,4,7]$ or of molecular compositions [5759].

One could also remark that the spectrometer's parameters may not be directly comparable leading to the convolution of the 'true' signal and the distortion of the spectrometer and thus to a broadening, and an accompanied decrease in intensity of the observed peaks, as it was observed with our 600 lines $\mathrm{mm}^{-1}$ grating, whereas literature data were obtained in ${ }^{7} \mathrm{~F}_{0} \rightarrow{ }^{5} \mathrm{D}_{0}$ excitation $[13,14,28,47,54]$. Nevertheless, the good agreement between the full-width at mid-height of previous humics data and the resolution of the peaks is a strong indication of a significant difference between "simple complexant" and our results.

The ${ }^{5} \mathrm{D}_{0} \rightarrow{ }^{7} \mathrm{~F}_{1}$ transition does not seem to undertake such evident modification for each sample, in line with the independence of this magnetic dipole transition to the ligand field.

\subsection{Evolution of the ${ }^{5} \mathrm{D}_{0} \rightarrow{ }^{7} \mathrm{~F}_{2}$ transition at 1800 lines $\mathrm{mm}^{-1}$.}

Concerning the ${ }^{5} \mathrm{D}_{0} \rightarrow{ }^{7} \mathrm{~F}_{2}$ hypersensitive transition, there is almost no modification of the maxima intensity between 614.35 and $614.44 \mathrm{~nm}$ for SRFA and SRHA, but weak interesting and significant modifications can be seen at the shoulder around $612 \mathrm{~nm}$. The average of normalized intensities of five pixels around $612.25 \mathrm{~nm}$ on Figure 3B,E are reported on Figure 4. The error bars $(2 \sigma)$ are the results of the propagation of uncertainties between $I_{\max }\left({ }^{7} \mathrm{~F}_{2}\right)$ and $\mathrm{I}_{612.25 \mathrm{~nm}}$, and the straight lines through the points are given as guide to the eye. For the two $\mathrm{Eu}(\mathrm{III})-\mathrm{HS}$ complexes, the relative fluorescence intensity of the $612 \mathrm{~nm}$ shoulder is decreasing. It is worthy to notice that this shoulder in ${ }^{5} \mathrm{D}_{0} \rightarrow{ }^{7} \mathrm{~F}_{2}$ was identified as being one of the main difference between the humic extracts from different origins analyzed in a previous work [41]. Even if it seems difficult to unambiguously ascertain the decrease of this shoulder, due to the uncertainty of this fluorescence ratio, these slight modifications could also be linked to a difference in the symmetry of the $\mathrm{Eu}(\mathrm{III})$-HS complexes with delay through a change in the splitting of the ${ }^{5} \mathrm{D}_{0} \rightarrow{ }^{7} \mathrm{~F}_{2}$ level. This is another indication which adds to the unambiguous decrease in symmetry previously evidenced from changes in the ${ }^{5} \mathrm{D}_{0} \rightarrow{ }^{7} \mathrm{~F}_{0}$ transitions. Without line narrowing experiment at lower temperature, no assignment to point symmetry group can be done but it must be more symmetric than $\mathrm{D}_{2 \mathrm{~h}}$ as no splitting in the ${ }^{5} \mathrm{D}_{0} \rightarrow{ }^{7} \mathrm{~F}_{1}$ transition can be observed [60]. Nevertheless, it seems that a double radiative process, involving two different excited species, is involved in the biexponential decay. 


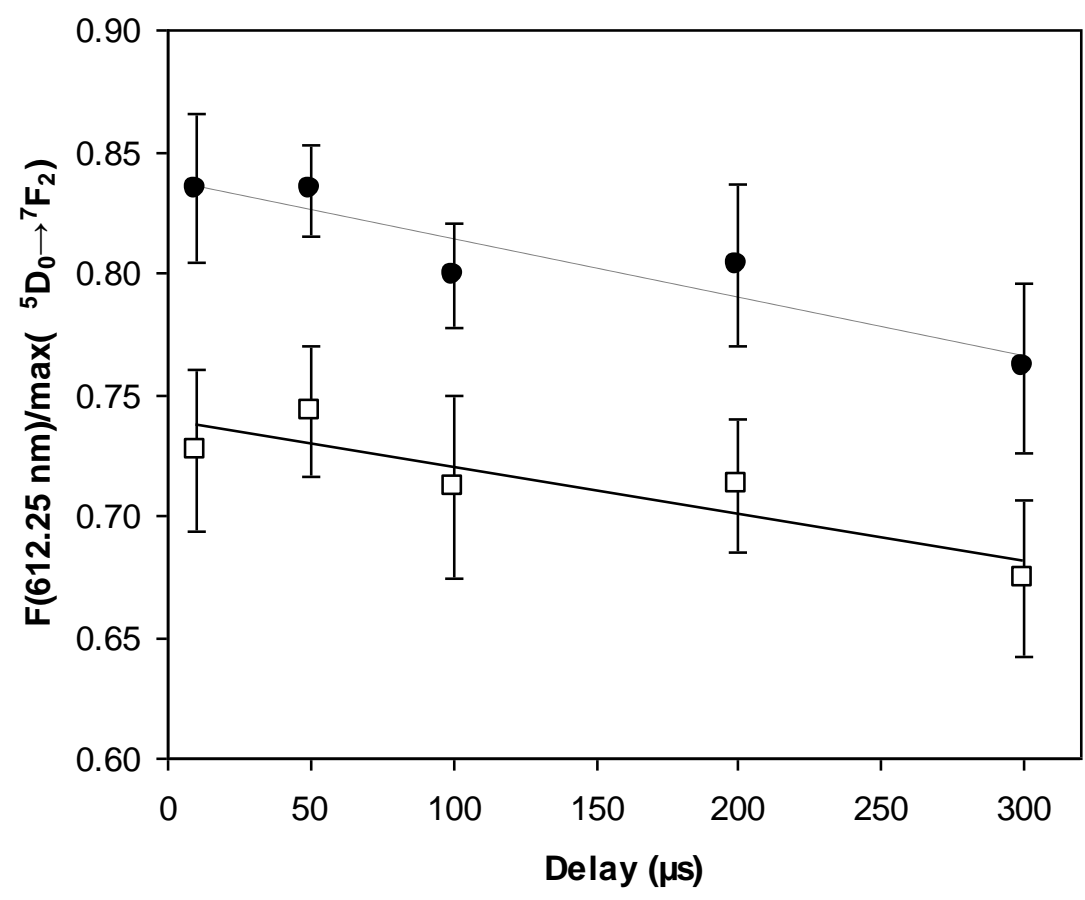

Figure 4: Normalized fluorescence intensities at $\lambda_{\mathrm{em}}=612.25 \pm 0.05 \mathrm{~nm}$ shoulder in Eu(III)-SRFA (full circle, from Figure 3B, ) and $\mathrm{Eu}(\mathrm{III})-\mathrm{SRHA}$ (empty square, from Figure $3 \mathrm{E}$ ). $[\mathrm{Eu}]=10^{-5} \mathrm{~mol}$ $\mathrm{L}^{-1}, \mathrm{pH}=5, I=0.1 \mathrm{~mol} \mathrm{~L}^{-1}\left(\mathrm{NaClO}_{4}\right)$.

\subsection{Decomposition of the radiative component.}

It can be postulated that two different radiative processes can be identified during the luminescence decay of Eu(III)-HS complexes using the 1800 lines $\mathrm{mm}^{-1}$ grating. From the modelled decay of $\mathrm{Eu}(\mathrm{III})-\mathrm{SRFA}$ and $\mathrm{Eu}(\mathrm{III})-\mathrm{SRHA}$ [41], it becomes evident that the contribution of the 'fast' component $1, \tau_{1}=41 \pm 5 \mu \mathrm{s}$, is totally suppressed after a $300 \mu \mathrm{s}$ delay. At this delay time, it accounts for $0.4_{5} \pm 0.0_{4} \%$ of the total Eu(III)-SRFA complex luminescence; the total luminescence signal at a $300 \mu$ s delay represents $7.9 \pm 0.5 \%$ of the luminescence at $10 \mu$ s delay. The spectrum of the 'slow' component $\mathrm{C} 2$ can then be considered to be the one at $D=300 \mu \mathrm{s}$ (dashed line on Figure 5A). Knowing the decay time of this 'slow' $\mathrm{C} 2$ [41], i.e., $\tau_{2}=144 \pm 6 \mu \mathrm{s}$, and that it contributes to $58.8 \pm 4.0 \%$ of the luminescence at $D=10 \mu \mathrm{s}$, the normalized signal of this component 2 can be subtracted to the luminescence signal at $D=10 \mu$ s to obtain the spectrum of the 'fast' component $\mathrm{C} 1$ (dotted line on Figure 5A). It is then evident that the two contributions have different spectra. The ${ }^{5} \mathrm{D}_{0} \rightarrow{ }^{7} \mathrm{~F}_{0} /{ }^{5} \mathrm{D}_{0} \rightarrow{ }^{7} \mathrm{~F}_{1}$ ratios of 1.1 and 0.8 for the 'fast' and 'slow' components, respectively, can be obtained. Similarly, the ${ }^{5} \mathrm{D}_{0} \rightarrow{ }^{7} \mathrm{~F}_{2} /{ }^{5} \mathrm{D}_{0} \rightarrow{ }^{7} \mathrm{~F}_{1}$ ratios are around 3.4 and 3.9 for the fast and slow component, respectively.

The same treatment can be done for the $\mathrm{Eu}$ (III)-SRHA complex. Under these conditions, $\tau_{1}=53 \pm$ $6 \mu \mathrm{s}$ and $\tau_{2}=191 \pm 12 \mu \mathrm{s}$ [41], which means that the 'fast' $\mathrm{C} 1$ component only contributes to $1.4 \pm$ $0.3 \%$ of the luminescence at $D=300 \mu \mathrm{s}$. Using the same approximation than in the case of Eu(III)-SRFA, the 'slow' component C2 contributes to $57.4 \pm 12.4 \%$ of the total luminescence at $D=$ $10 \mu \mathrm{s}$, and the spectra can be proposed (Figure 5B). The two contributions end in different spectra: ${ }^{5} \mathrm{D}_{0} \rightarrow{ }^{7} \mathrm{~F}_{0} /{ }^{5} \mathrm{D}_{0} \rightarrow{ }^{7} \mathrm{~F}_{1}$ ratios of 1.2 and 0.7 , and the ${ }^{5} \mathrm{D}_{0} \rightarrow{ }^{7} \mathrm{~F}_{2} /{ }^{5} \mathrm{D}_{0} \rightarrow{ }^{7} \mathrm{~F}_{1}$ ratios are around 3.6 and 3.9 for the 'fast' and 'slow' components, respectively. These values are less reliable than in the case of Eu(III)-SRFA due to the higher uncertainties of the parameters of the fit [41]. 

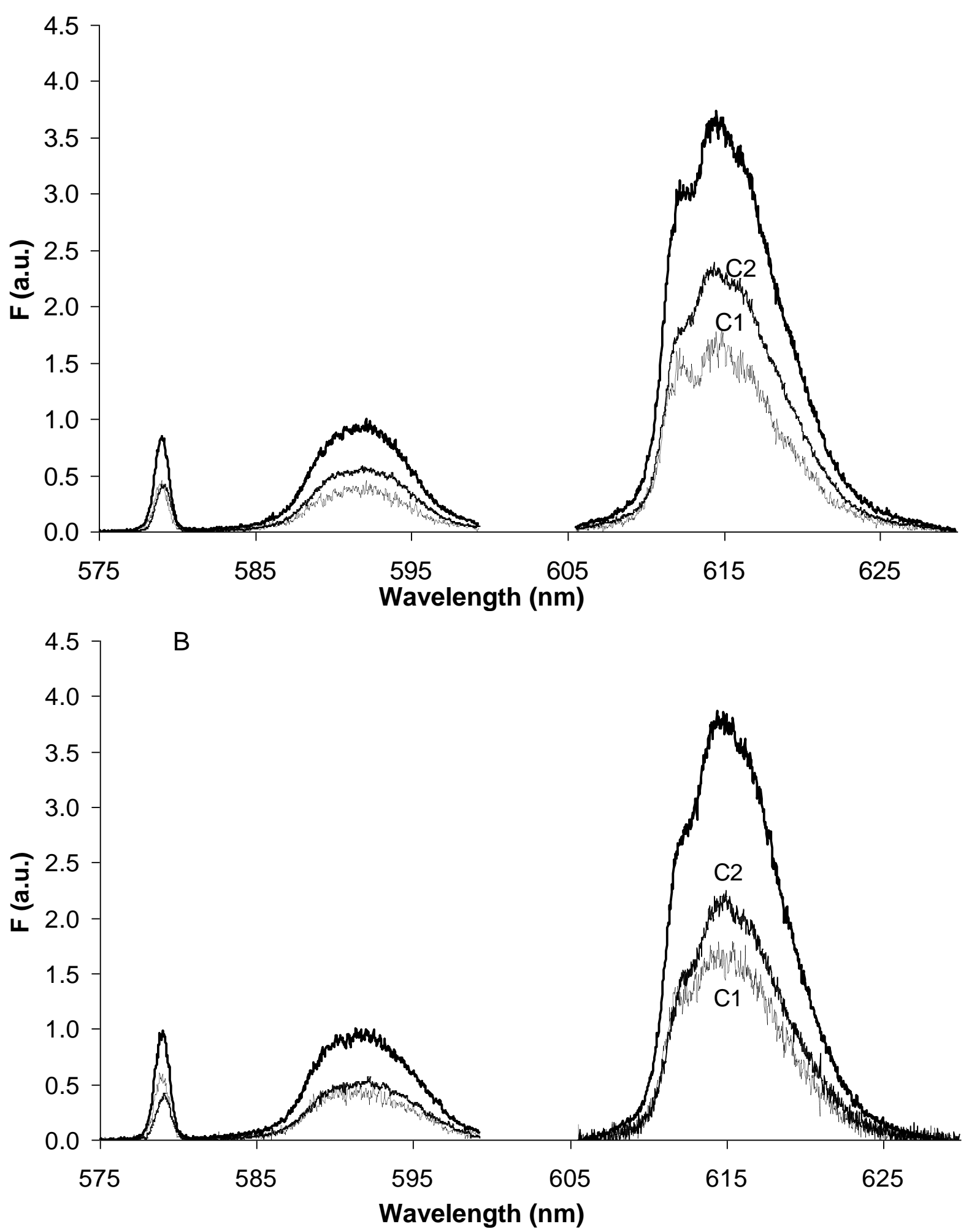

Figure 5. Spectra of Eu(III)-HS complexes (bold plain line) at $\lambda_{\mathrm{exc}}=394.6 \mathrm{~nm}, D=10 \mu \mathrm{s}, W=300$ $\mu \mathrm{s}$, of Eu-SRFA (A) and Eu-SRHA (B) complexes, and spectra of the slow component (C2, thin plain) at $D=300 \mu \mathrm{s}, W=300 \mu \mathrm{s}$ normalized to its relative importance at $D=10 \mu \mathrm{s}$; the spectrum of the fast components $(\mathrm{C} 1$, dotted line) are obtained subtracting $\mathrm{C} 2$ from the signal $\mathrm{F}$ at $D=10 \mu \mathrm{s}$.

The occurrence of a bi-exponential decay was not solely observed in the case of humic complexes. Fujiwara et al. [31], observed also a bi-exponential decay of two complexes between Eu(III) 4,4,4trifluoro-1-(2-thienyl)-1,3-butanedione and 4,7-diphenyl-1,10-phenanthroline disulfonate at the toluene-water interface. Tsukahara et al. [32], observed that in the presence of thenoyl trifluoroacetone (TTA), EuTTA ${ }^{2+}$ complex undergone a luminescence decay with $k_{1}=3.610^{4} \mathrm{~s}^{-1}\left(\tau_{1}=27.7 \mu \mathrm{s}\right)$ and $k_{2}$ 
$=5.7810^{3} \mathrm{~s}^{-1}\left(\tau_{2}=173 \mu \mathrm{s}\right)$. The authors proposed that the Eu*-TTA ${ }^{2+}$ excited complex can undergo a deactivation to Eu-TTA ${ }^{2+}$ and a dissociation reaction $\left(\left(\mathrm{Eu}^{3+}\right)^{*}+\mathrm{TTA}^{-}\right)$. The fast component, i.e., $k_{1}=$ $1 / \tau_{1}$, being the deactivation of $\left(\mathrm{Eu}^{3+}\right)^{*}$, after the dissociation of $\mathrm{Eu}^{*}-\mathrm{TTA}^{2+}$, and the slow component, i.e., $k_{2}=1 / \tau_{2}$, being the sum of the dissociation of $\mathrm{Eu}^{*}-\mathrm{TTA}^{2+}$ and of its deactivation. The system of equation was solved with the hypothesis that Eu-TTA ${ }^{2+}$ complex should have seven remaining water molecules. This reaction and deactivation scheme is difficult to be fully applied here as we do not have enough information about the hydration number of the humic complexe(s). Particularly, the influence of $\mathrm{D}_{2} \mathrm{O}$ in the particular humic mixtures is not fully clarified for $\mathrm{Ln} / \mathrm{An}(\mathrm{III})$. Under these conditions one could come to the conclusion, after Tsukahara et al. scheme [32], that the slow component $\mathrm{C} 2$ could be the spectrum of the excited complex, and fast component $\mathrm{C} 1$ could be the spectrum of the excited $(\mathrm{Eu}) *$ in the system.

Freyer et al. also proposed a fast exchange mechanism between $\mathrm{Cm}^{3+}$ and $\mathrm{Cm}(\mathrm{III})-\mathrm{HA}$ complex [33] when $\mathrm{pH} \leq 5.5$, but comparing the results is difficult because Freyer et al. seem to detect the characteristic luminescence spectrum of $\mathrm{Cm}^{3+}$ both in $\mathrm{D}_{2} \mathrm{O}$ and $\mathrm{H}_{2} \mathrm{O}\left(\lambda_{\max }=594 \mathrm{~nm}, \tau_{1} \approx \tau_{\mathrm{Cm}^{3+}}\right.$, while the spectrum we are obtaining at low delay is not characteristic of $\mathrm{Eu}^{3+}\left({ }^{5} \mathrm{D}_{0} \rightarrow{ }^{7} \mathrm{~F}_{2} /{ }^{5} \mathrm{D}_{0} \rightarrow{ }^{7} \mathrm{~F}_{1}=0.25\right)$. Also the reasons of the luminescence quenching $\left(\tau_{1} \leq \tau_{\mathrm{Eu}^{3^{+}}}\right)$is not clear. As recalled earlier, either Förster resonance or Dexter energy transfer are likely in humic substances' structure. It is thus likely that the excited $(\mathrm{Eu})^{*}$ is more efficiently quenched than $(\mathrm{Cm})^{*}$. Regarding the ${ }^{5} \mathrm{D}_{0} \rightarrow{ }^{7} \mathrm{~F}_{2} /{ }^{5} \mathrm{D}_{0} \rightarrow{ }^{7} \mathrm{~F}_{1}$ ratios and spectra, this means that only few differences exist between these species in term of symmetry because $(\mathrm{Eu})^{*}$ seem to be still be under the influence of the complexation environment [33].

Billard \& Lützenkirchen [61] proposed that in the case of a fast exchange mechanism, where photochemical processes are not fast enough to fully mix the excited states, the apparent decay time values should change with the concentration of ligand. This was observed in two of our previous studies were Eu(III) was fully complexed by the same HA sample from Gorleben, Germany [11, 41], but was not put in relation until now. In Marang et al. for $\mathrm{c}_{\mathrm{Eu}}=7 \mu \mathrm{mol} \mathrm{L} \mathrm{L}^{-1}$ and $\mathrm{c}_{\mathrm{HA}}=20 \mathrm{mg} \mathrm{L}^{-1}(I=1$ $\left.\mathrm{mmol}_{\mathrm{NO}_{3}} \mathrm{~L}^{-1}, 99.2 \% \mathrm{Eu}-\mathrm{HA}, 2.86 \mathrm{mg}_{\mathrm{AH}} \mathrm{mol}_{\mathrm{Eu}}^{-1}\right), \tau_{1}=17 \pm 2 \mu \mathrm{s}$ and $\tau_{2}=135 \pm 2 \mu$ s were obtained [11], whereas in Brevet et al. for $\mathrm{c}_{\mathrm{Eu}}=10 \mu \mathrm{mol} \mathrm{L}^{-1}$ and $\mathrm{c}_{\mathrm{HA}}=200 \mathrm{mg} \mathrm{L}^{-1}\left(I=0.1 \mathrm{~mol}_{\mathrm{ClO}_{4}} \mathrm{~L}^{-1}, 99.4 \%\right.$ of Eu$\left.\mathrm{HA}, 20 \mathrm{mg}_{\mathrm{HA}} \mathrm{mol}_{\mathrm{Eu}}^{-1}\right), \tau_{1}=60 \pm 6 \mu$ s and $\tau_{2}=172 \pm 11 \mu$ s were obtained [41]. Further works are in progress to ascertain this trend.

Another likely explanation would be two populations of complexes of relatively close symmetry, as proposed between two successive glycolate complexes by Stumpf et al. [62], or by Rabung and Geckeis [26] for fast and slow dissociating Eu(III)-HA complexes after the works from Monsallier $e t$ al. [30]. This interpretation would lead to two complexes of slightly different symmetry, as evidence by changes in shape of ${ }^{5} \mathrm{D}_{0} \rightarrow{ }^{7} \mathrm{~F}_{0}$ and ${ }^{5} \mathrm{D}_{0} \rightarrow{ }^{7} \mathrm{~F}_{2}$ transitions, but comparable complexation strength from the ${ }^{5} \mathrm{D}_{0} \rightarrow{ }^{7} \mathrm{~F}_{2} /{ }^{5} \mathrm{D}_{0} \rightarrow{ }^{7} \mathrm{~F}_{1}$ ratio. It is up to now not possible to firmly discriminate between these situations.

\section{Conclusion}

It is shown that the bi-exponential decay commonly observed for the luminescence of Eu(III)-HS complexes is the result of the deactivation of at least two different excited states. The main evolution of the luminescence spectra of the two decays resides in the ${ }^{5} \mathrm{D}_{0} \rightarrow{ }^{7} \mathrm{~F}_{0}$ transition. When increasing the delay of observation after the laser pulse, a decrease of the ${ }^{5} \mathrm{D}_{0} \rightarrow{ }^{7} \mathrm{~F}_{0} /{ }^{5} \mathrm{D}_{0} \rightarrow{ }^{7} \mathrm{~F}_{1}$ ratio is clearly evidenced, as well as a slight red shift of the ${ }^{5} \mathrm{D}_{0} \rightarrow{ }^{7} \mathrm{~F}_{0}$ transition. The ${ }^{5} \mathrm{D}_{0} \rightarrow{ }^{7} \mathrm{~F}_{1}$ transition do not seem to undergo any noticeable change, but the shoulder around $612 \mathrm{~nm}$ of the ${ }^{5} \mathrm{D}_{0} \rightarrow{ }^{7} \mathrm{~F}_{2}$ transition, already 
implied in the differences of luminescence spectra of Eu(III)-HS complexes of different origins [41], is submitted to a subtle decrease with delay. Both the decrease of ${ }^{5} \mathrm{D}_{0} \rightarrow{ }^{7} \mathrm{~F}_{0}$ transition and slight modification of ${ }^{5} \mathrm{D}_{0} \rightarrow{ }^{7} \mathrm{~F}_{2}$ transition are indications of at least two species sharing a very close symmetry. It is then possible that the fast component of the bi-exponential decay could be a dissociated excited species $(\mathrm{Eu})^{*}$, still under the influence of the ligand field induced by the HS environment and/or a fast exchanging humic species. This fast component exhibiting a decay time shorter than the aquo $\mathrm{Eu}^{3+}$ is submitted to quenching mechanisms by the chromophores within the humic structure. Further works are required in order to discriminate the component of the slow component, which should be composed of the eigen luminescence decay of the $\left(\mathrm{Eu}^{*}\right)-\mathrm{HS}$ excited complex, and its dissociation to $\mathrm{Eu}^{*}+\mathrm{HS}$, to ascertain the mechanism.

\section{Acknowledgements}

We thank Drs. Thomas Vercouter (CEA), Clemens Walther (INE) and François Viala (CEA) for helpful discussions. This work was financed through the "FUNMIG project" (EC: FUNMIGNUWASTE-2004-3.2.1.1-1), and the MRTRA project of the Risk Control Domain (CEA/DEN/DDIN) and the CHSOL project of the RdB Domain (CEA/DEN/DSOE) of CEA

\section{References}

[1] A.M. Posner, J. Soil Sci. 17 (1966) 65.

[2] E.M. Perdue, C.R. Lytle, Environ. Sci. Technol. 17 (1983) 654-660.

[3] G.R. Choppin, B. Allard, Complexes of actinides with naturally occurring organic compounds, in: A.J.

Freeman and C. Keller (Eds.), Handbook on the Physics and Chemistry of the Actinides, Elsevier, 1985, pp. 407429.

[4] R.S. Altmann, J. Buffle, Geochim. Cosmochim. Acta 52 (1988) 1505-1519.

[5] P. Warwick, A. Hall, D. Read, Radiochim. Acta 66/67 (1994) 133-140.

[6] H.S. Shin, B.H. Lee, H.B. Yang, S.S. Yun, H. Moon, J. Radioanal. Nucl. Chem. 209 (1996) 123-133.

[7] D.G. Kinniburgh, W.H. van Riemsdijk, L.K. Koopal, M. Borkovec, M.F. Benedetti, M.J. Avena, Colloids Surf. A 151 (1999) 147-166.

[8] E. Tipping, Aquat. Geochem. 4 (1998) 3-48.

[9] J.W. Thomason, W. Susetyo, L.A. Carreira, Appl. Spectrosc. 50 (1996) 401-408.

[10] L. Marang, P.E. Reiller, S. Eidner, M.U. Kumke, M.F. Benedetti, Environ. Sci. Technol. 42 (2008) 50945098.

[11] L. Marang, S. Eidner, M.U. Kumke, M.F. Benedetti, P.E. Reiller, Chem. Geol. 264 (2009) 154-161.

[12] T.H. Yoon, H. Moon, Y.J. Park, K.K. Park, Environ. Sci. Technol. 28 (1994) 2139-2146.

[13] H.S. Shin, S.W. Rhee, B.H. Lee, C.H. Moon, Org. Geochem. 24 (1996) 523-529.

[14] H.S. Shin, G.R. Choppin, Radiochim. Acta 86 (1999) 167-174.

[15] J.C. Dobbs, W. Susetyo, F.E. Knight, M.A. Castles, L.A. Carreira, L.V. Azarraga, Anal. Chem. 61 (1989) 486-488.

[16] G. Bidoglio, I. Grenthe, Q. P., P. Robouch, N. Omenetto, Talanta 38 (1991) 999-1008.

[17] C. Moulin, P. Decambox, P. Mauchien, V. Moulin, M. Theyssier, Radiochim. Acta 52/53 (1991) 119-125.
[18] A. Dierckx, A. Maes, J. Vancluysen, Radiochim. Acta 66/67 (1994) 149-156.

[19] K.R. Czerwinski, J.I. Kim, D.S. Rhee, G. Buckau, Radiochim. Acta 72 (1996) 179-187.

[20] C. Moulin, J. Wei, P. van Iseghem, I. Laszak, G. Plancque, V. Moulin, Anal. Chim. Acta 396 (1999) 253261.

[21] J.I. Kim, D.S. Rhee, G. Buckau, A. Morgenstern, Radiochim. Acta 79 (1997) 173-181.

[22] M. Morgenstern, R. Klenze, J.I. Kim, Radiochim. Acta 88 (2000) 7-16.

[23] G. Plancque, V. Moulin, P. Toulhoat, C. Moulin, Anal. Chim. Acta 478 (2003) 11-22.

[24] K.H. Chung, W. Lee, Y. Cho, G. Choi, C. Lee, Talanta 65 (2005) 389-395.

[25] M.U. Kumke, S. Eidner, T. Kruger, Environ. Sci. Technol. 39 (2005) 9528-9533.

[26] T. Rabung, H. Geckeis, Radiochim. Acta 97 (2009) 265-271.

[27] W.D. Horrocks, D.R. Sudnick, J. Am. Chem. Soc.

101 (1979) 334-340.

[28] W.D. Horrocks, D.R. Sudnick, Accounts of Chemical Research 14 (1981) 384-392.

[29] N. Sabbatini, M. Guardigli, J.-M. Lehn, Coordination Chemistry Reviews 123 (1993) 201-228.

[30] J.M. Monsallier, W. Schussler, G. Buckau, T.

Rabung, J.I. Kim, D. Jones, R. Keepax, N. Bryan, Anal. Chem. 75 (2003) 3168-3174.

[31] M. Fujiwara, S. Tsukahara, H. Watarai, Phys. Chem. Chem. Phys. 1 (1999) 2949-2951.

[32] S. Tsukahara, M. Fujiwara, H. Watarai, Chemistry Letters (2000) 412-413.

[33] M. Freyer, C. Walther, T. Stumpf, G. Buckau, T. Fanghänel, Radiochim. Acta 97 (2009) 547-558.

[34] B. Alpha, R. Ballardini, V. Balzani, J.-M. Lehn, S. Perathoner, N. Sabbatini, Photochem. Photobiol. 52 (1990) 299-306.

[35] A. Bruccoleri, B.C. Pant, D.K. Sharma, C.H. Langford, Environ. Sci. Technol. 27 (1993) 889-894. 
[36] R.G. Zepp, P.F. Schlotzhauer, R.M. Sink, Environ. Sci. Technol. 19 (1985) 74-81.

[37] M.T. Berry, P.S. May, H. Xu, J. Phys. Chem. 100 (1996) 9216-9222.

[38] T. Stumpf, G. Buckau, T. Fanghänel, Coordination of trivalent actinides by humic acids: A TRLFS study, in: G. Buckau (Ed.), Humic substances in performance assessment of nuclear waste disposal: actinide and iodine migration in the far-field. Third technical report, FZKINE, Report FZKA 7070,

http://bibliothek.fzk.de/zb/berichte/FZKA7070.pdf, 2005, pp. 1-8.

[39] B.R. Judd, Phys. Rev. 127 (1962) 750-761.

[40] G.S. Ofelt, Journal of Chemical Physics 37 (1962) 511-520.

[41] J. Brevet, F. Claret, P.E. Reiller, Spectrochimica Acta A 74 (2009) 446-453.

[42] C.J. Milne, D.G. Kinniburgh, E. Tipping, Environ. Sci. Technol. 35 (2001) 2049-2059.

[43] J.D. Ritchie, E.M. Perdue, Geochim. Cosmochim. Acta 67 (2003) 85-96.

[44] C.J. Milne, D.G. Kinniburgh, W.H. Van Riemsdijk, E. Tipping, Environ. Sci. Technol. 37 (2003) 958-971. [45] J.C.G. Bünzli, Luminescent probes, in: J.C.G. Bünzli and G.R. Choppin (Eds.), Lanthanides probe in life, chemical and earth sciences - Theory and practice, Elsevier, 1989, pp.

[46] J.M. Monsallier, F.J. Scherbaum, G. Buckau, J.I. Kim, M.U. Kumke, C.H. Specht, F.H. Frimmel, J. Photochem. Photobiol. A 138 (2001) 55-63. [47] S.T. Frey, W.D. Horrocks, Inorg. Chim. Acta 229 (1995) 383-390.
[48] M. Albin, W.D. Horrocks, Inorg. Chem. 24 (1985) 895-900.

[49] G.R. Choppin, Z.M. Wang, Inorg. Chem. 36 (1997) 249-252.

[50] C.W. McNemar, W.D. Horrocks, Appl. Spectrosc. 43 (1989) 816-821.

[51] R. de Levie, Advanced Excel for Scientific Data Analysis, Oxford University Press, 2005.

[52] M. Albin, B.M. Cader, W.D. Horrocks, Inorg. Chem. 23 (1984) 3045-3050.

[53] N.J. Turro, Modern molecular photochemistry, University Science Books, Sausalito, CA, USA., 1991. [54] M.F. Yeh, T. Riedener, K.L. Bray, S.B. Clark, J. Alloys Comp. 303 (2000) 37-41.

[55] S.E. Burroughs, G. Eisenman, W.D. Horrocks, Biophys. Chem. 42 (1992) 249-256.

[56] R. Del Vecchio, N.V. Blough, Environ. Sci. Technol. 38 (2004) 3885-3891.

[57] V. Moulin, P. Reiller, B. Amekraz, C. Moulin, Rapid Commun. Mass Spectrom. 15 (2001) 2488-2496. [58] P. Reiller, B. Amekraz, C. Moulin, Environ. Sci. Technol. 40 (2006) 2235-2241.

[59] A. These, M. Winkler, C. Thomas, T. Reemtsma, Rapid Commun. Mass Spectrom. 18 (2004) 1777-1786. [60] M. Albin, A.C. Goldstone, A.S. Withers, W.D. Horrocks, Inorg. Chem. 22 (1983) 3182-3184.

[61] I. Billard, K. Lutzenkirchen, Radiochim. Acta 91 (2003) 285-294.

[62] T. Stumpf, T. Fanghänel, I. Grenthe, J. Chem. Soc.Dalton Trans. (2002) 3799-3804. 